\section{DESENVOLVIMENTO PROFISSIONAL DOCENTE NO PROGRAMA SEGUNDO TEMPO UNIVERSITÁRIO NA UNIVERSIDADE FEDERAL DE MATO GROSSO DO SUL}

\author{
CONTINUING PROFESSIONAL DEVELOPMENT IN THE SEGUNDO \\ TEMPO UNIVERSITY PROGRAM AT THE FEDERAL UNIVERSITY OF \\ MATO GROSSO DO SUL CP
}

DESARROLLO PROFESIONAL DOCENTE EN EL PROGRAMA SEGUNDO TIEMPO UNIVERSITARIO EN LA UNIVERSIDAD FEDERAL DE MATO GROSSO DO SUL CP

doi) https://doi.org/10.22456/1982-8918.111746

(D) Dirceu Santos Silva* <dirceu_09@yahoo.com.br>

(D) Paulo Vinicius Baroni Silveira Donadon*<paulovdonadon@gmail.com>

(D) Marina Brasiliano Salerno* <marina.brasiliano@ufms.br>

(iD) Breno Brey D’auria* <b_brey@hotmail.com>

(i) Luiza Lana Gonçalves* <luiza.lana@ufms.br>

*Universidade Federal de Mato Grosso do Sul (UFMS). Campo Grande, MS, Brasil

Resumo: O objetivo foi analisar o desenvolvimento profissional docente (DPD) dos monitores esportivos e do professor que atuaram no Programa Segundo Tempo (PST) Universitário na Universidade Federal de Mato Grosso do Sul (UFMS). Tratouse de uma pesquisa descritiva, com abordagem qualitativa. O software Iramuteq foi utilizado para a análise dos dados das entrevistas semiestruturadas. Os resultados indicaram que, apesar das atividades iniciais de formação previstas nas diretrizes do PST Universitário não terem sido oferecidas aos monitores e professor do núcleo, as atividades semanais foram fundamentais para o DPD. A atuação no programa permitiu uma reflexão sobre as metodologias indicadas pelo programa em consonância com as disciplinas da graduação, a autoavaliação do ensino-aprendizagem e a construção da identidade do ser professor. Concluiu-se que o PST Universitário na UFMS possibilitou o DPD contínuo e contextualizado com a futura prática docente.

Palavras chave: Política Pública. Programas Sociais. Capacitação Profissional. Esportes
Recebido em: 02 fev. 2021 Aprovado em: 20 abr. 2021 Publicado em: 09 jun. 2021

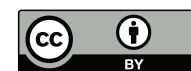

Este é um artigo publicado sob a licença Creative Commons Atribuição 4.0 Internacional (CC BY 4.0). elSSN: 1982-8918 


\section{INTRODUÇÃO}

Nas últimas duas décadas, pesquisas sobre o desenvolvimento profissional em programas sociais de esporte educacional ganharam destaque no Brasil, sobretudo após a criação do Ministério do Esporte, no ano de 2003. A criação de uma pasta ministerial possibilitou a estruturação do Programa Segundo Tempo (PST), em 2003, permitindo o crescimento de pesquisas relacionadas ao desenvolvimento profissional e pedagógico no âmbito do PST (RIBEIRO; ISAYAMA, 2015; UNGHERI; ISAYAMA, 2017; SOUZA et al., 2018; PIZANI et al., 2020).

O PST busca o atendimento do direito constitucional de acesso ao esporte educacional e apresenta três vertentes: o PST Padrão, ofertado às crianças, aos adolescentes e jovens de 6 a 17 anos no contraturno escolar; o PST Paradesporto, que atende pessoas com deficiência a partir dos 6 anos de idade; o PST Universitário, criado em 2009, ofertado aos discentes das Instituições de Ensino Superior (IES) (BRASIL, 2020).

O PST Universitário busca democratizar o acesso à prática do esporte educacional na promoção do desenvolvimento integral como fator de formação de cidadania e melhoria da qualidade de vida da comunidade universitária, prioritariamente o corpo discente. O programa faz uma previsão de contratação via edital público de um professor de Educação Física ou esporte e três monitores esportivos, acadêmicos de Educação Física. A meta de cada núcleo do PST Universitário envolve o atendimento de 300 beneficiários em modalidades esportivas coletivas e individuais. A carga horária do programa inclui 20 horas para o professor e 20 para os monitores, sendo 15 horas para o oferecimento de atividades aos discentes e 5 horas semanais de planejamento/formação. Dessa forma, o programa tem uma previsão de desenvolvimento profissional dos monitores esportivos e professor antes e ao longo da realização do convênio (BRASIL, 2018).

Por desenvolvimento profissional docente (DPD), entende-se as múltiplas oportunidades de aprendizagem em que os professores ou futuros professores se envolvem durante sua trajetória de formação para aprender e para aperfeiçoar a sua atuação profissional (DAY; SACHS, 2004). No campo esportivo, professores que se dedicam a ensinar práticas corporais em diversos contextos devem ser compreendidos como aprendizes que se desenvolvem ao longo de toda vida (ARMOUR, 2011). Essa concepção ampla de DPD pretende extrapolar a dicotomia da formação inicial/ continuada e superar a visão da formação como algo externo, que pode ser adquirido em cursos de curta duração ou em atividades isoladas. Os professores "aprendem e se desenvolvem profissionalmente mediante participação em diferentes práticas, processos e contextos, intencionais ou não, que promovem a formação ou a melhoria da prática docente" (FIORENTINI; CRECCI, 2013, p. 13).

Pesquisas têm apontado maneiras efetivas de promover o DPD, dentre elas têm-se destacado as atividades: a) colaborativas, quando as pessoas são encorajadas a compartilhar seu aprendizado e experiências; b) por meio de suporte mútuo para o enfrentamento dos desafios ao longo de suas trajetórias de aprendizagem (HIGGINS et al., 2015; HARGREAVES; O'CONNOR, 2017). Além disso, as ações de 
DPD devem ser organizadas em torno da prática profissional situadas no contexto da aprendizagem de maneira contínua e com suporte ao aprendizado autônomo, reflexivo e inovador daqueles profissionais (ARMOUR, 2011).

Embora esses fatores já estejam presentes na construção teórica sobre o DPD, o que se vê é uma formação composta por cursos de curta duração, afastados dos problemas cotidianos da prática e que pouco contribuem para um aprendizado efetivo (FERREIRA; SANTOS; COSTA, 2015; JONES; ARMOUR; POLTRAC, 2003). No contexto da formação inicial, o problema se torna ainda maior. Os acadêmicos muitas vezes recebem uma grande carga horária teórica nos seus cursos iniciais de graduação e não estabelecem vínculo com a futura prática pedagógica (GARIGLIO, 2010; MARCON; NASCIMENTO; GRAÇA, 2007; UNGHERI; ISAYAMA, 2017). Como consequência, passam a enfrentar os desafios do distanciamento da formação com o campo de intervenção de maneira isolada, após sua graduação, no contexto profissional (ARMOUR; YELLING, 2007; MACHADO et al., 2010).

Nesse sentido, o PST Universitário, ao prever ações de DPD nas diretrizes nacionais, torna-se um espaço favorável para o desenvolvimento profissional de monitores e professores que atuam/atuaram no núcleo. Nas diretrizes do programa destaca-se que a formação para atuar com o esporte educacional pode proporcionar uma aprendizagem dos monitores e professores em relação à área de atuação e à realidade dos beneficiários, além de fomentar pesquisas científicas destinadas ao aprimoramento dos profissionais que atuam com o esporte educacional/universitário (BRASIL, 2018).

Segundo as diretrizes do PST Universitário 2018, a estruturação das ações de DPD de professores e monitores esportivos ocorre por meio da parceria entre a Secretaria Nacional de Esporte, Educação, Lazer e Inclusão Social (SENELIS) do Ministério da Cidadania e as IES. As diretrizes fazem uma previsão de: a) capacitação inicial $^{1}$ na modalidade presencial (20 a 40 dias após o início das atividades) e capacitação modelo Ensino a Distância - EaD + Presencial (6 semanas); b) formação continuada, com cursos e uso de material didático; c) planejamento, reuniões com os colaboradores e grupos de estudos de projetos esportivos que ocorrem semanalmente; d) acompanhamento e avaliações de visitas aos núcleos (OLIVEIRA et al., 2016; BRASIL, 2018).

As atividades de DPD do PST Universitário estão baseadas na proposta do PST padrão, que apresenta os fundamentos pedagógicos da obra de Oliveira e Perim (2009). As iniciativas ocorrem por meio da Equipe Pedagógica (EP), responsável pela estruturação e desenvolvimento do processo de formação e de Equipes Colaboradoras (ECs), compostas por professores mestres e doutores de diferentes IES do país. A EP e as ECs são responsáveis pela formação, assessoria ao planejamento, visitas de acompanhamento e avaliação do núcleo (OLIVEIRA et al., 2016).

1 Diferentes nomenclaturas já foram utilizadas para denominar o processo de aprendizagem e desenvolvimento do professor que ocorre ao longo de toda a vida (DAY; SACHS, 2004; ARMOUR, 2011). Termos como capacitação e reciclagem podem representar cursos de curta duração ou capacitações pontuais e esporádicas, hierarquizadas e descontextualizadas que têm se mostrado pouco efetivas (NUNES; OLIVEIRA, 2017). Assim, todos os termos descritos aqui são nomenclaturas utilizadas nas diretrizes nacionais do PST Universitário e não representam a orientação teórica dos autores. 
Estudos sobre o PST padrão levantaram dados nacionais sobre formação profissional e acompanhamento pedagógico (OLIVEIRA et al., 2016; PIZANI et al., 2020), e, apesar de relatos acerca das ações de DPD em programas sociais esportivos, identificaram-se escassas investigações acerca das experiências de DPD no PST Universitário (GONÇALVES; SILVA; MARINS, 2019).

Dessa forma, o objetivo do artigo foi analisar o DPD dos monitores esportivos e do professor que atuaram no PST Universitário na UFMS. Especificamente, duas questões guiaram esta pesquisa: como foram desenvolvidas as ações de DPD no convênio do PST Universitário na Universidade Federal de Mato Grosso do Sul (UFMS)? Qual é a percepção do professor e monitores esportivos sobre o processo de DPD no PST Universitário?

\section{METODOLOGIA}

A presente pesquisa envolveu o método descritivo, que utilizou a abordagem qualitativa, justificada por privilegiar a dimensão processual do conhecimento do DPD do PST Universitário na UFMS (BOGDAN; BIKLEN, 1994).

\subsection{O CONTEXTO DA PESQUISA NO PST UNIVERSITÁRIO NA UFMS}

O projeto do PST Universitário na UFMS foi submetido ao Edital de Chamada Pública n. ${ }^{\circ}$ 01/2017. A aprovação ocorreu via SENELIS, na época vinculada ao Ministério do Esporte, por meio da Portaria n. ${ }^{\circ}$ 11, de 4 de setembro de 2017 (BRASIL, 2017a). O convênio entre o Governo Federal e a UFMS foi assinado via Termo de Execução Descentralizada n. ${ }^{\circ}$ 20/2017, por 24 meses, entre 26 de dezembro de 2017 e 26 de dezembro de 2019 (BRASIL, 2017b). Do total, seis meses são destinadas para estruturação e 18 meses para oferta de atividades para os beneficiários. No entanto, a estruturação do programa atrasou oito meses e as atividades se iniciaram apenas em 18 de março de 2019 (BRASIL, 2018). O programa atendeu 504 acadêmicos até o momento de realização desta pesquisa. As atividades de DPD previstas nas diretrizes, como a formação inicial presencial ou $\mathrm{EaD}$, não ocorreram antes da execução do convênio. Dessa forma, consideraramse para a análise as experiências formativas desenvolvidas durante a execução do convênio, sobretudo as 15 horas semanais dedicadas ao oferecimento das modalidades esportivas e as cinco horas de planejamento/formação continuada (BRASIL, 2017b; BRASIL, 2018).

\subsection{PROCEDIMENTOS DE PESQUISA}

Cinco entrevistados participaram como voluntários: quatro acadêmicos do curso de licenciatura em Educação Física e um professor do curso de Educação Física da UFMS, o que representou todos os profissionais que atuaram no convênio pesquisado, conforme Quadro 1. 
Quadro 1 - Caracterização dos sujeitos da pesquisa

\begin{tabular}{|c|c|c|c|}
\hline $\mathbf{N}$ & Sexo/ldade & Tempo de atuação & Função no PST Universitário \\
\hline M1 & Masculino/20 anos & 1 ano e 3 meses & $\begin{array}{c}\text { Monitor de futebol (society), futsal, handebol e } \\
\text { grupo de corrida. }\end{array}$ \\
\hline M2 & Masculino/21 anos & 5 meses & $\begin{array}{c}\text { Monitor de voleibol, vôlei de praia, } \\
\text { basquetebol e tênis. }\end{array}$ \\
\hline M3 & Masculino/22 anos & 9 meses & $\begin{array}{c}\text { Monitor de voleibol, vôlei de praia, } \\
\text { basquetebol e futevôlei. }\end{array}$ \\
\hline M4 & Feminino/23 anos & 1 ano e 3 meses & $\begin{array}{c}\text { Monitora de musculação e treinamento } \\
\text { funcional. }\end{array}$ \\
\hline P1 & Masculino/34 anos & 1 ano e 3 meses & Professor do núcleo. \\
\hline
\end{tabular}

Fonte: dados da pesquisa

O procedimento de coleta de dados foi realizado por meio de entrevistas semiestruturadas (MAY, 2004). Antes da coleta de dados, o roteiro de entrevista foi analisado por três professores doutores especialistas, que indicaram a necessidade de readequação de perguntas ao instrumento. Após essa fase, houve o estudo piloto com um dos monitores esportivos, como forma de aperfeiçoar o instrumento de pesquisa. O questionário final envolveu questões sobre: a) como ocorreu o processo de DPD dos profissionais; b) quais experiências pessoais contribuíram para atuação no programa; c) quais experiências da formação inicial da graduação foram mais significativas para atuação; d) qual o impacto do programa na sua vida profissional; e) de que forma o programa pode influenciar na construção da identidade do ser professor; f) quais foram os pontos positivos e negativos.

As entrevistas foram realizadas via Google Meet, em período agendado com os sujeitos da pesquisa entre os meses de abril e julho de 2020. As entrevistas foram gravadas e posteriormente transcritas (no total de 15 páginas). A entrevista seguiu todos os requisitos éticos e foi aprovado pelo Comitê de Ética em Pesquisa da UFMS, número do parecer: 3.831.263.

Os arquivos com as transcrições foram organizados no programa OpenOffice Writer e foram codificados pelo software Iramuteq (Interface de $R$ pour les Analyses Multidimensionnelles de Textes et de Questionnaires) (RATINAUD, 2009), hospedado no software R. A análise dos dados textuais foi utilizada para a elaboração das classes.

A análise gerada pelo programa Iramuteq permite a tabulação dos dados com a elaboração de um corpus textual para realizar a análise pelo método Reinert ou classificação hierárquica descendente (CHD). Esse método permite que os segmentos de textos sejam classificados de acordo com a frequência dos vocábulos, além de demonstrar os elementos que se destacam na formação de classes (CAMARGO; JUSTO, 2013). Ressalta-se que apenas os elementos que atenderam a um critério preestabelecido $\left[X^{2}(1) \geq 3,84, p<0,01\right]$ foram selecionados, por indicarem maior relevância dentro da classe formulada, com apresentação complementar dos principais discursos.

A partir das classes geradas, analisaram-se os principais vocábulos, com a apresentação dos trechos mais representativos de cada categoria. As classes 
representam o corpus textual e os trechos das entrevistas não foram identificados por questões éticas. Por fim, utilizou-se nuvem de palavras gerada pelo Iramuteq para demonstração gráfica dos principais vocábulos. A análise realizada permitiu a organização dos resultados das entrevistas em duas etapas: 1. A CHD gerou o dendograma das classes, que demonstra a associação das classes entre si; 2. Agrupamento e representação gráfica da nuvem de palavras com a frequência dos principais vocábulos.

O corpus textual gerado a partir das cinco entrevistas apresentou 137 segmentos de texto (ST), com uma média de 35,64 palavras com radicais distintos, com um total de 4.884 ocorrências (total de palavras). A divisão total foi realizada em 101 ST, $79,72 \%$ da análise do corpus textual, percentual considerado significativo para análise via Iramuteq $(\geq 70 \%)$.

\section{RESULTADOS}

$\mathrm{Na}$ primeira etapa de análise, a CHD permitiu identificar seis classes no dendograma, nomeadas de acordo com a temática. Identificou-se a correlação entre as classes, sem se distanciar da temática do corpus textual que é o DPD. Todas as classes expressam aspectos do eixo norteador do estudo, mas destacam pontos relevantes para a compreensão da prática. A relação entre as classes foi apresentada na Figura 1.

Figura 1 - Dendograma e classificação hierárquica descendente

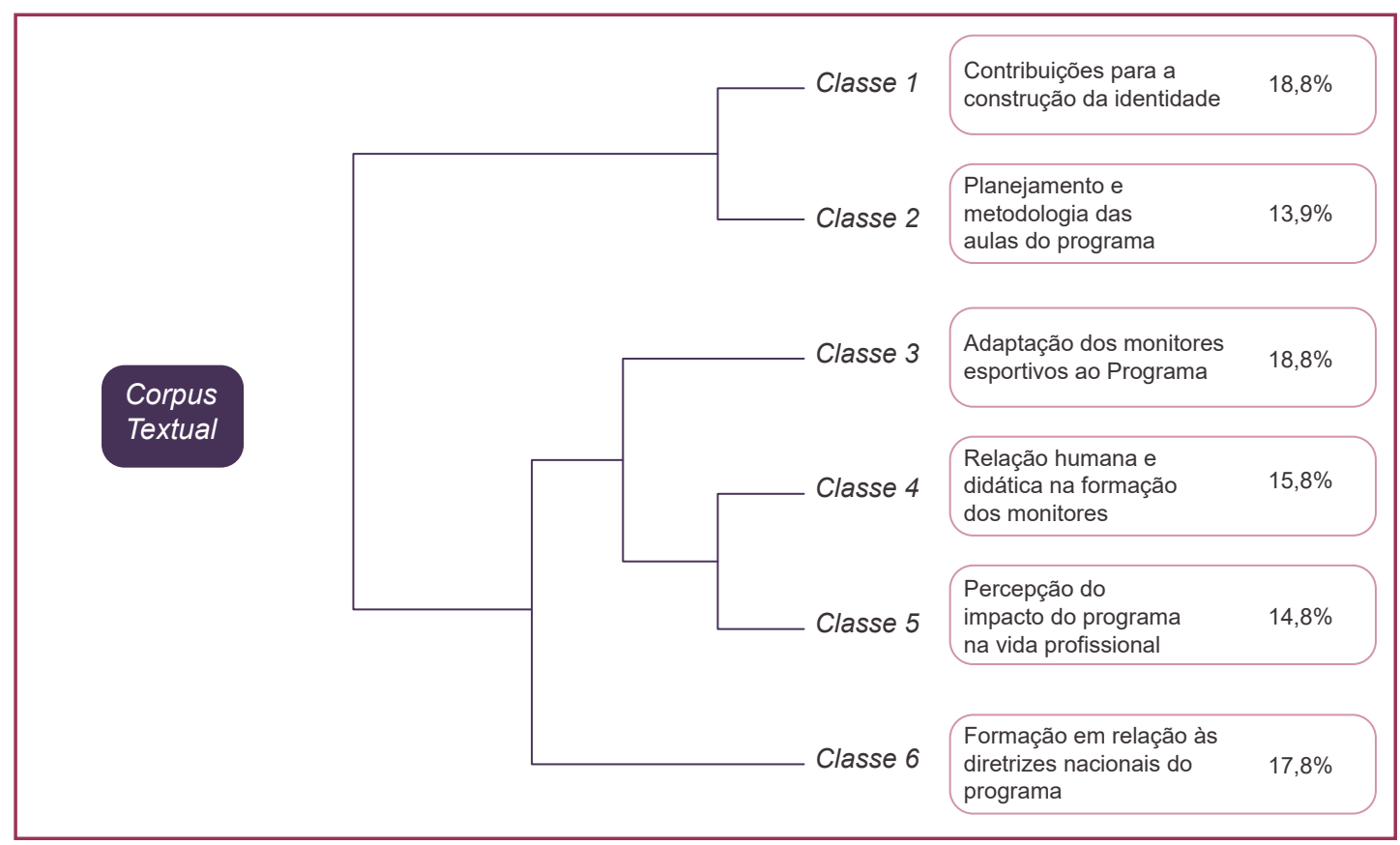

Fonte: dados da pesquisa

A partir do dendograma da Figura 1, o corpus textual gerado das entrevistas foi subdividido pelo programa em dois subcorpora. O primeiro subcorpus foi subdividido e foi composto pelas classes 1 e 2 , que representaram elementos que se aproximam da análise da contribuição do PST Universitário para o DPD dos monitores e professor, tanto para a construção da identidade, quanto para a aprendizagem sobre 
o planejamento e as metodologias de ensino. O segundo subcorpus contém as classes de 3 a 6 , e retrata as percepções dos entrevistados a respeito dos diferentes fatores que estão envolvidos no DPD.

A classe $1\left(\mathrm{ST}_{\text {Classe } 1}=19\right.$, que explica $18,80 \%$ do total) foi denominada "Contribuições para a construção da identidade". As falas dos sujeitos que compõem essa classe pontuaram que a atuação profissional no PST Universitário contribuiu para ação e reflexão sobre a prática, bem como para a aquisição de saberes e competências para a intervenção em programas sociais esportivos. Na percepção dos entrevistados, o programa proporcionou a construção de um sentimento de pertencimento, identidade e integração universitária, como demonstrado nos trechos das entrevistas a seguir:

[...] existem oficinas teóricas e práticas que fazem com que o monitor esportivo realize uma reflexão sobre a teoria e prática, e uma avaliação das ideias gerais que podem contribuir significativamente para o aperfeiçoamento e melhoria do PST Universitário.

[...] de resolução de problemas e de ocupação do tempo livre desses estudantes com o uso do esporte educacional como forma de lazer na vida do acadêmico, que pode contribuir, por exemplo, para ele criar um grupo ou uma identidade na universidade.

[...] pode evitar a evasão dos acadêmicos da universidade ou de algum curso, além de contribuir para criação da identidade com a universidade, então o programa acho que é um meio para essa integração do universitário.

A classe $2\left(\mathrm{ST}_{\text {Classe } 2}=14\right.$, que explica $13,90 \%$ do total) foi denominada de "Planejamento e metodologia das aulas do programa". As entrevistas indicaram que o aprendizado da metodologia utilizada no programa está associado ao currículo da graduação, sobretudo às disciplinas de pedagogia do esporte e didática. As entrevistas destacaram que o planejamento semanal realizado coletivamente permitiu a reflexão sobre a prática pedagógica, como descrito nos recortes das entrevistas a seguir:

[...] o impacto do programa na vida profissional dos monitores esportivos é ainda mais significativo, já que cada um teve que aplicar 15 horas semanais de diferentes modalidades esportivas de forma planejada e a partir de pesquisas científicas.

[...] didática, currículo e outras disciplinas são de grande relevância na formação e contribuem para atuação dos monitores nas oficinas práticas do programa. Eu acredito que o planejamento contribui para alinhar todas as oficinas e para os monitores compartilharem as experiências positivas e negativas semanalmente.

[...] já que o programa destaca essa metodologia no material didático do PST e nas diretrizes do PST Universitário, isto é, o planejamento das aulas destaca a pedagogia do esporte, ensino por meio do jogo.

Nota-se que a correlação estabelecida entre as primeiras classes promove a reflexão acerca de pontos relevantes do PST Universitário para os entrevistados: a construção da identidade; a aprendizagem de metodologias relacionadas à formação inicial; a integração dos monitores esportivos com a universidade; o sentimento de pertencimento da comunidade acadêmica na participação das oficinas esportivas e a interação entre professor e monitores esportivos no planejamento, momento em que pode ocorrer a reflexão sobre o contexto, formação e o retorno positivo ou negativo das propostas. 
No segundo subcorpus do dendograma, o programa subdividiu o texto em outras quatro classes, que têm correlação entre si e se relacionam com os diferentes fatores que estão envolvidos na realização do PST Universitário. A classe 3 (ST $=19$, que explica $18,80 \%$ do total) foi denominada de "Adaptação dos monitores esportivos ao Programa", e representa tanto a adaptação da rotina dos monitores para participar do programa, quanto às exigências da universidade. A adaptação da rotina está relacionada à inserção da organização temporal dos monitores, na conciliação entre disciplinas e demais atividades acadêmicas. A adaptação às exigências do programa, por sua vez, diz respeito à necessidade de planejar e ministrar modalidades esportivas. Por exemplo, o tênis não faz parte do currículo da graduação, mas os monitores tiveram que superar os desafios cotidianamente. As adaptações dos entrevistados foram descritas nos trechos a seguir:

[...] agora entrou a modalidade de tênis e também não temos essa disciplina no curso de Educação Física, ficando muito difícil às vezes para executar uma atividade, quando não se tem uma formação inicial.

[...] então acabei escolhendo o PST Universitário às disciplinas em alguns momentos, mas isso não acontece sempre porque meus horários são teoricamente intervalo, então não bate com nenhuma disciplina.

[...] é pesado porque são muitas horas por semana, então, às vezes, eu não tenho um tempo hábil para fazer um trabalho com 'calma', então, às vezes eu faço um trabalho um pouco menos dedicado, que eu faria se eu não tivesse no PST Universitário.

A classe $4\left(\mathrm{ST}_{\text {Classe } 4}=16\right.$, que explica $15,80 \%$ do total) foi denominada de "Relação humana e didática na formação dos monitores", uma vez que contempla elementos referentes à didática e a seus saberes. Essa classe descreve a questão afetiva da relação humana, que envolve a valorização prévia das experiências do beneficiário, respeito e acolhimento a quem se ensina. O Planejamento Pedagógico do Convênio (PPC) assegura a busca pela inclusão e participação ativa dos beneficiários de forma a evitar desmotivações (UFMS, 2018). Esse plano estabelece uma relação direta com as falas da entrevista a seguir:

[...] no meu caso é complexo, se você só deixar a pessoa fazer o movimento do jeito que ela quiser, pode machucar, então eu tenho que buscar a correção, mas respeitando a individualidade e valorizando as experiências da pessoa.

[...] acho que para minha vida profissional vai ser muito impactante no sentido positivo, o PST Universitário tem uma atuação mais crítica do que as abordagens mais tradicionais da Educação Física.

[...] porque é assim que eu aprendi, assim que eu vou ser, isso não é aprender com a sua experiência, acho que, se você consegue aprender, você vai se tornar um professor melhor, vai trazendo mais pessoas para perto.

A classe $5\left(\mathrm{ST}_{\text {Classe } 5}=15\right.$, que explica $14,80 \%$ do total) foi denominada de "Percepção do impacto do programa na vida profissional", e explicita os resultados do programa para aprendizagem dos monitores e do professor. O PST Universitário permitiu a aprendizagem de como ser professor, a assimilação de novos métodos de ensino e prática de modalidades não vivenciadas no curso de graduação, além da reflexão sobre o processo de ensino e aprendizagem, conforme trechos das entrevistas a seguir: 
[...] acaba sendo um impacto bem positivo, por mais que o PST Universitário não tenha acabado [o projeto foi suspenso] por conta da pandemia do Covid-19, eu acho que melhorou muito a questão de como ser um profissional da minha área.

[...] eu aprendi coisas que não sabia, como vôlei de praia, tendo que aprender do zero para dar aula, tive que melhorar bastante minha didática porque explicar para outras pessoas parece ser fácil, mas existem pessoas que não entendem.

[...] A gente tem essa formação, então tem situação que a gente olha depois da oficina e pensa em como poderíamos ter agido diferente, porque acabei de aprender isso, mas não tinha conseguido ver na prática.

A classe $6\left(\mathrm{ST}_{\text {Classe6 }}=18\right.$, que explica $17,80 \%$ do total) foi denominada de "Formação em relação às diretrizes nacionais do Programa". Os dados analisados permitiram indicar que a formação inicial e o acompanhamento pedagógico previstas nas diretrizes nacionais do PST Universitário (BRASIL, 2018) não foram oferecidas para os monitores e professor que atuaram no núcleo na UFMS. Dessa forma, houve uma dissociação entre o previsto nas diretrizes nacionais e o realizado no convênio. Enfrentaram-se também outras dificuldades, tais como: lidar com um contexto político incerto de extinção do Ministério do Esporte em 2019. Os trechos da entrevista a seguir exemplificam tais resultados:

[...] a formação inicial não ocorreu, foi até um tema muito discutido durante as reuniões, e o Ministério da Cidadania era para ter dado essa formação inicial, mas não ocorreu até o presente momento em que estava no PST Universitário.

[...] Porque todo o contato que a gente tinha e também o momento político não estava propício para isso, foi quando o Ministério do Esporte foi extinto e foi criada a Secretaria Especial do Esporte dentro do Ministério da Cidadania.

[...] eu acho que isso foi uma dificuldade na verdade, foi um desafio de fazer essa formação interna, só com os professores voluntários, no entanto, já que essa formação inicial do Ministério não ocorreu dentro do princípio das diretrizes.

A partir do detalhamento das classes e da correlação apresentada na Figura 1, entende-se que houve a relevância indicada a partir da associação da percepção do impacto do programa na vida profissional (Classe 5) e das relações humanas e didáticas (Classe 4), já que se aproxima do que é aprendido na graduação na interação entre professores e alunos. Essas relações são influenciadas pelos aspectos organizacionais das oficinas, com alteração de horários e propostas ao longo dos semestres para adaptação às obrigações discentes, bem como na percepção das lacunas da formação (Classe 3).

A partir das relações estabelecidas, entende-se que o segundo subcorpus aponta para fatores como: relevância da interação monitor/beneficiário para o DPD; relação teoria/prática a partir da compreensão de sua indissociabilidade; dificuldades organizacionais do programa com as obrigações discentes; ausência do cumprimento da formação indicada nas diretrizes nacionais do PST Universitário; aprendizagem sobre o que e como ensinar a partir da interação com as disciplinas da graduação e a reflexão sobre a prática durante a formação contínua.

Para complementar os resultados, a nuvem de palavras permitiu agrupar e organizar graficamente uma análise lexical, além de permitir a apresentação dos 
principais vocábulos do corpus textual, com sua frequência percebida pelo tamanho do texto. Identificou-se a relação entre os termos "formação", "professor" e "PST Universitário" como as mais mencionadas, diretamente relacionadas com o DPD. A Figura 2 mostra que as palavras que os entrevistados destacaram remetem ao processo de formação e prática das modalidades esportivas.

Figura 2 - Nuvem de Palavras

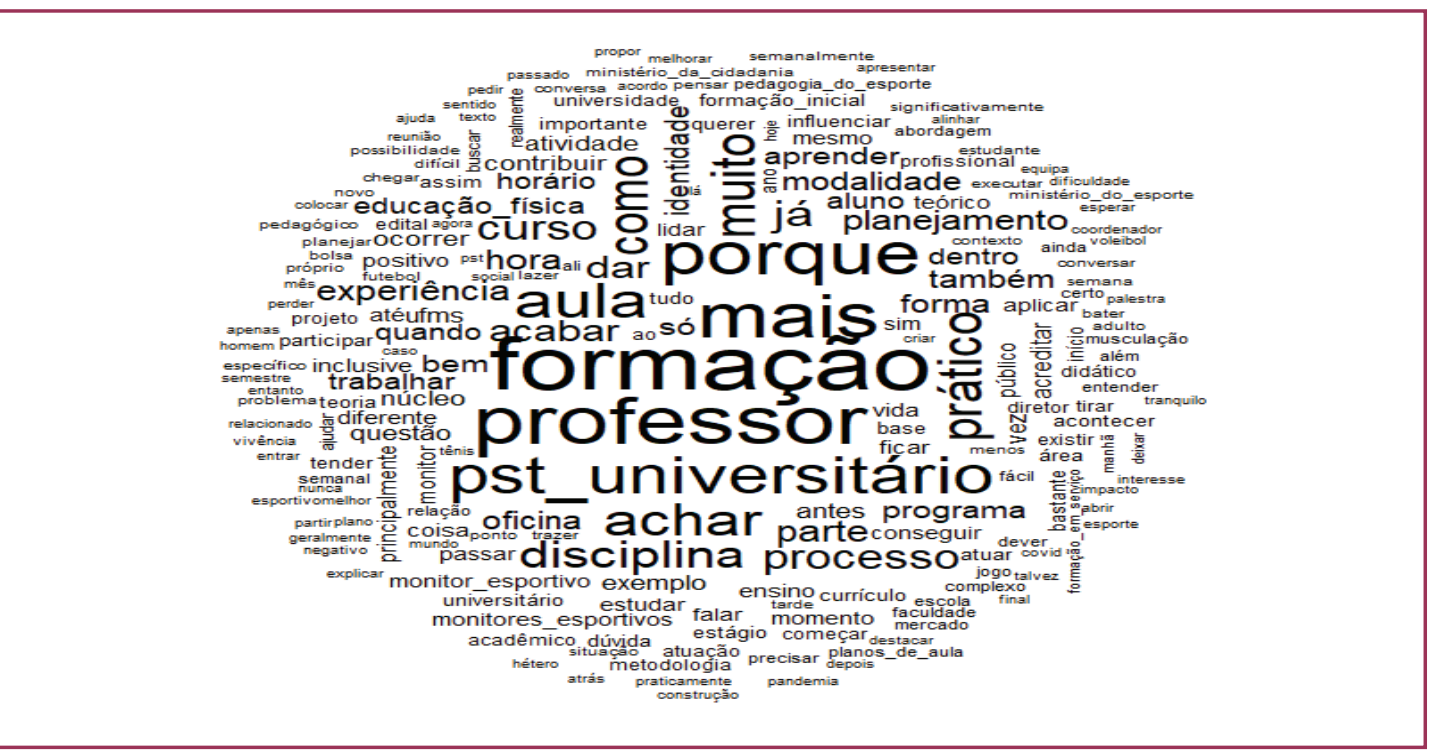

Fonte: dados da pesquisa

Como ferramenta de processamento de informações nos dados das entrevistas realizadas, a nuvem de palavras permitiu mostrar os desafios da formação e do DPD na percepção dos sujeitos. Reportou-se ainda que a experiência como monitor esportivo no PST Universitário foi um aspecto facilitador na construção da identidade do professor e proporcionou aperfeiçoamento da didática e da aprendizagem para a atuação em programas sociais de esporte educacional.

\section{DISCUSSÃO}

Ao analisar o DPD dos sujeitos que atuaram no PST Universitário na UFMS, é possível perceber que os encontros semanais com o grupo foram fundamentais para a formação, para a reflexão sobre as metodologias indicadas pelas diretrizes nacionais em consonância com as disciplinas da graduação; a autoavaliação do processo de ensino e de aprendizagem; a construção da identidade do ser professor. A fim de detalhar tais resultados, dividimos a discussão em três seções: a) desafios para o DPD no PST universitário; b) importância da formação contínua para o desenvolvimento do programa; c) a relação entre a participação no PST Universitário e o DPD dos monitores e professor.

\subsection{DESAFIOS PARA O DPD NO PST UNIVERSITÁRIO}

Ao longo da realização do programa, alguns fatores que se constituíram como desafios para o DPD no PST Universitário na UFMS foram percebidos. Primeiro, o programa foi operado sem as ECs, assessoria pedagógica presencial e à distância. 
Sabe-se que a formação contínua e a assessoria pedagógica desempenham papel importante na condução do PST (ARAÚJO et al., 2012; OLIVEIRA et al., 2016; RIBEIRO; ISAYAMA, 2015), no entanto, a Secretaria Especial do Esporte do Ministério da Cidadania repassou os recursos para a realização do convênio na UFMS, mas não realizou o DPD previsto nas diretrizes nacionais, fato destacado na Classe 6. A ausência de formação contínua e assessoria pedagógica não foi comum em outros convênios. Em pesquisas desenvolvidas por Araújo et al. (2012), Oliveira et al. (2016) e Ribeiro e Isayama (2015), foi possível realizar uma análise sobre a formação oferecida pelas ECs.

De acordo com Oliveira et al. (2016), a capacitação inicial deveria ser oferecida nas modalidades "presencial" ou "ensino a distância $(\mathrm{EaD})+$ presencial" a partir de nove temáticas centrais: 1. Fundamentos do PST; 2. Fundamentos do lazer e animação cultural; 3. Corpo, gênero e sexualidade; 4. Desenvolvimento e aprendizagem motora; 5. Questões da deficiência e as ações do PST; 6. Organização e desenvolvimento pedagógico; 7. Procedimentos metodológicos; 8. Planejamento do PST; 9. Atividades Práticas. No caso de convênios como o do PST Universitário, com um núcleo (ou em convênios com até 20 núcleos), os monitores são incluídos em uma formação mais ampla da mesma cidade ou estado, o que não ocorreu com o convênio pesquisado.

De acordo com Silva, Borges e Roeldes (2014), a formação é um elemento fundamental para a qualidade do conteúdo da ação política e configura como elemento central para a garantia do esporte como direito. Ao analisarem a formação de um programa social esportivo, constataram uma descontinuidade da formação entre um convênio e outro, bem como um distanciamento entre o previsto nas diretrizes nacionais para a formação e o que se materializou na prática.

Como desafio para o DPD dos sujeitos envolvidos no PST Universitário em âmbito nacional, sugere-se a formação contínua sobre os princípios do programa. Dessa forma, a descentralização de recursos financeiros, conforme ocorreu no convênio pesquisado, sem nenhum tipo DPD, não permite a troca de experiências entre diferentes convênios do Brasil. A ausência da formação indicada na Classe 6 abre margem para discussões sobre a efetivação e responsabilidades dos entes pagadores das políticas públicas no desenvolvimento profissional e, ainda que não seja o objetivo do presente estudo, devem ser investigados para melhor compreensão de seus efeitos, já que foi percebida pelos sujeitos que atuaram no convênio.

\subsection{IMPORTÂNCIA DA FORMAÇÃO CONTÍNUA PARA O DESENVOLVIMENTO DO PROGRAMA}

Diante da ausência das atividades iniciais de formação no PST Universitário, os entrevistados tiveram que se adaptar e, em um processo contínuo de aprendizagem, entender as metodologias de ensino do programa, as novas modalidades esportivas que deveriam ser ofertadas e o próprio processo de como ensinar, conforme descrito na classe 5. Nessa situação, reuniões de planejamento semanais se tornaram espaços coletivos de aprendizagem e contribuíram para o DPD. 
De acordo com estudos sobre o processo de DPD, a aprendizagem dos sujeitos não ocorre de maneira fragmentada, depende de um processo contínuo de reflexão e ação ao longo da trajetória de atuação do indivíduo (FIORENTINI; CRECCI, 2013; NUNES; OLIVEIRA, 2017). Os sujeitos demonstraram que durante os encontros semanais, em um processo cíclico, conseguiram aplicar e refletir posteriormente sobre suas práticas pedagógicas, discutir suas dificuldades com seus pares e experimentar novas estratégias e metodologias de ensino que correspondem às necessidades do seu contexto.

Sabe-se que as atividades iniciais de formação podem atuar como inclusão desses monitores esportivos e do professor nas orientações necessárias ao programa, assim como na ambientação com as diretrizes e metodologias (ARAÚJO et al., 2012). Entretanto, como relatado por Ungheri e Isayama (2017), em outros programas esportivos, a experiência com as atividades iniciais de formação não é suficiente para desenvolver a aprendizagem necessária para atuação no programa.

De acordo com Oliveira et al. (2016), 20\% dos professores e monitores esportivos apontaram que as formações do PST raramente atendem às suas necessidades pedagógicas, ao passo que as ECs do programa consideravam que as reuniões são estratégias mais eficazes de DPD.

Embora não tenha se avaliado o impacto do programa no desenvolvimento do curso de Educação Física, os dados da presente pesquisa demonstram que, na perspectiva dos monitores e professor, é no contexto de formação contínua e coletiva que o aprendizado para trabalhar no programa se desenvolve. Tal resultado potencializa novas perspectivas para a formação no PST universitário.

\subsection{A RELAÇÃO ENTRE A PARTICIPAÇÃO NO PST UNIVERSITÁRIO E O DPD DOS MONITORES E PROFESSOR}

Nos cursos de graduação em Educação Física, a prática pedagógica é enfatizada - seja nos estágios ou outras atividades - como elemento importante na formação do acadêmico (BRASIL, 2018b). Essa experimentação constitui uma oportunidade para aprender a docência. Os acadêmicos, imersos em situações reais de ensino, lidam com as demandas da prática, aprendem as funções específicas do ser professor (MARCON; GRAÇA; NASCIMENTO, 2012). Além de contribuir com a aprendizagem dos conhecimentos pedagógicos do conteúdo (MARCON; NASCIMENTO; GRAÇA, 2007), a imersão em atividades de prática pedagógica no decorrer dos cursos de graduação ajuda a constituir os saberes da experiência (SILVA; BRACHT, 2005), tornando-se a tendência chave nos cursos de formação na área de Educação Física (NÍ CHRÓNIN; O’SULLIVAN, 2014).

Os sujeitos do presente estudo demonstraram valorizar a oportunidade de aprendizagem a partir da experiência, como demonstrado na classe 4. A formação para atuação em programas sociais de esporte educacional não deve se basear exclusivamente em disciplinas acadêmicas, uma vez que os conhecimentos e conteúdos podem emergir de diferentes formas. Ungheri e Isayama (2017) salientaram que os saberes da intervenção profissional podem se enquadrar em quatro eixos: 1. 
Os saberes específicos da área (esporte); 2. Os saberes relacionados às políticas; 3. Os saberes ligados à gestão; 4 . Os saberes que envolvem a prática profissional. Uma questão presente nos dados das entrevistas foi o conhecimento sobre o PST Universitário em âmbito nacional, os saberes sobre as diretrizes do programa, a fonte pagadora, as responsabilidades das instituições e a metodologia de ensino.

Segundo Ungheri e Isayama (2017) é necessário compreender o conhecimento peculiar das diretrizes nacionais dos programas e inserir o esporte no contexto da prática. Esses saberes, quando materializados em ações, traduzem-se em competências necessárias para a intervenção profissional no cotidiano.

Assim, o processo de constituição da identidade do ser professor foi se fortalecendo no decorrer da participação no programa. Na classe 1 destacamos que os sujeitos relataram o convênio como uma oportunidade de exercer a prática pedagógica por meio da relação entre ação-reflexão-ação. Entende-se que é por meio da vivência das práticas pedagógicas que a identidade docente se estabelece (PIRES et al., 2017). Na relação entre os conhecimentos adquiridos nas disciplinas e as práticas no ensino, o acadêmico incorpora:

[...] sentimentos e ações que influenciam o entendimento de ser professor, nomeadamente os valores internalizados pelos professores, o entendimento de como cada um constrói sua história, as posições docentes implicadas pelas visões de mundo, as representações da docência, os saberes, as expectativas e as frustrações (PIRES et al., 2017, p. 42-43).

Percebemos que o PST Universitário proporcionou um espaço de reflexão coletiva, o que contribui para a construção da identidade docente. De forma semelhante, Fletcher (2012) afirma que as experiências práticas de ensino são permeadas por momentos de reflexão coletiva que podem produzir novos entendimentos sobre a prática e, de maneiras diferentes, solucionar problemas cotidianos.

A formação contínua se constituiu como um espaço de reflexão para desafiar concepções tradicionais sobre como ensinar (NÍ CHRÓNIN; O'SULLIVAN, 2014). Dados de uma pesquisa sobre o PST destacaram a relevância da reflexão sobre a prática para a ação docente, sobretudo a sequência pedagógica e metodológica (SOUZA et al., 2018). No presente estudo, os sujeitos reconheceram que não só aprenderam novos conteúdos, mas também refletiram sobre o processo de ensino e aprendizagem.

\section{CONSIDERAÇÕES FINAIS}

Ao final desta pesquisa, podemos inferir que na percepção dos entrevistados, apesar de não seguir as diretrizes nacionais, o PST Universitário contribuiu significativamente para um DPD contínuo e contextualizado com a futura prática docente. A pesquisa demonstrou que a formação contínua, realizada por meio das oficinas e reuniões semanais de planejamento, constituiu-se como elemento importante para o funcionamento do programa e para a aprendizagem dos sujeitos envolvidos. Essa aprendizagem não se refere somente aos conhecimentos necessários para atuar no programa, mas também à construção dos saberes para atuar como professor. 
Pesquisar o DPD nas políticas públicas de esporte educacional, nos modos como se ensina e se aprende a ser professor, é de fundamental importância para o avanço da produção científica e para um impacto real na sociedade. O processo de desenvolvimento profissional se constitui como um elemento central para o funcionamento adequado das modalidades esportivas dos convênios firmados entre o Governo Federal, municípios, estados e universidades. Assim, a apresentação de dados científicos para os professores, gestores, acadêmicos, monitores esportivos e órgãos idealizadores pode promover o aperfeiçoamento do DPD em políticas públicas, bem como a maximização dos resultados do investimento público.

Estudos futuros podem investir sobre tal temática, na busca do entendimento do impacto das atividades de DPD antes e depois do programa sobre a melhoria de atendimento aos beneficiários. Além disso, é necessário ouvir outros sujeitos envolvidos na realização do PST universitário, principalmente em convênios que receberam a formação da EP e das ECS, a fim de apontar diferentes estratégias para uma formação contínua e reflexiva dentro do programa e para uma atuação efetiva e de qualidade para os beneficiários.

\section{REFERÊNCIAS}

ARAÚJJ, Alyson Carvalho et al. Formação e Atuação Pedagógica no Programa Segundo Tempo: reflexões sobre o fazer cotidiano do professor. Motrivivência, v. XXIV, n. 38, p. 4052, 2012. Disponível em: https://periodicos.ufsc.br/index.php/motrivivencia/article/view/21758042.2012v24n38p40. Acesso em: 16 ago. 2020. DOI: https://doi.org/10.5007/21758042.2012v24n38p40.

ARMOUR, Kathleen. Effective career-long professional development for teachers and coaches. In: ARMOUR, Kathleen. (Org.) Sport pedagogy: an introduction for teaching and coaching. London: Routledge, 2011. p. 229-243.

ARMOUR, Kathleen; YELLING, Martin. Effective Professional Development for Physical Education Teachers: The Role of Informal, Collaborative Learning. Journal of Teaching in Physical Education, v. 26, n. 2, p. 177-200, Apr. 2007. Disponível em: https://journals. humankinetics.com/view/journals/jtpe/26/2/article-p177.xml. Acesso em: 15 set. 2019. DOI: https://doi.org/10.1123/jtpe.26.2.177

BOGDAN, Robert; BIKLEN, Sari. Investigação qualitativa em educação: uma introdução à teoria e aos métodos. Portugal: Porto Editora, 1994

BRASIL. Constituição da República Federativa do Brasil. Diário Oficial da República Federativa do Brasil. Brasília, DF: Senado Federal, 1988. 496 p. Disponível em: https:// www2.senado.leg.br/bdsf/bitstream/handle/id/518231/CF88 Livro EC91 2016.pdf. Acesso em: 15 set. 2019.

BRASIL. [Lei Pelé]. Lei n 9.615, de 24 de março de 1998. Diário Oficial da República Federativa do Brasil. Brasília, DF: Poder Executivo, 1998. Disponível em: https://www2. camara.leg.br/legin/fed/lei/1998/lei-9615-24-marco-1998-351240-publicacaooriginal-1-pl. html. Acesso em: 15 set. 2019. 
BRASIL. Portaria No 11, de 4 de setembro de 2017. Diário Oficial da República Federativa do Brasil. Brasília, DF: Ministério do Esporte. 2017a. Disponível em: https://www.in.gov.br/ materia/-lasset publisher/Kujrw0TZC2Mb/content/id/19277319/do1-2017-09-05-portaria-n11-de-4-de-setembro-de-2017-19277230. Acesso em: 6 set. 2020

BRASIL. Termo de Execução Descentralizada n 20/2017. Brasília, DF: Ministério do Esporte. 2017b. Disponível em: https://www.jusbrasil.com.br/diarios/277608052/dou-secao3-27-12-2019-pg-11. Acesso em: 05 set. 2020

BRASIL. Programa Segundo Tempo Universitário: diretrizes. Brasília, DF: Secretaria Especial do Esporte, 2018. Disponível em: http://arquivo.esporte.gov.br/arquivos/snelis/segundoTempo/ diretrizes/2019 0710 Diretrizes PST Padrao 2018.pdf. Acesso em: 15 set. 2019

BRASIL. Programa Segundo Tempo. Brasília, DF: Secretaria Especial do Esporte, 2020. Disponível em: http://arquivo.esporte.gov.br/index.php/institucional/esporte-educacao-lazere-inclusao-social/segundo-tempo. Acesso em: 15 set. 2019.

BRASIL. Conselho Nacional de Educação. Resolução CNE/CP n 6, de 18 de dezembro de 2018. Institui Diretrizes Curriculares Nacionais dos Cursos de Graduação em Educação Física. Brasília, DF: MEC/CNE/CP, 2018. Disponível em: https://www.in.gov. br/materia//asset_publisher/Kujrw0TZC2Mb/content/id/55877795. Acesso em: 31 de ago. 2020.

CAMARGO, Brigido Vizeu; JUSTO, Ana Maria. IRAMUTEQ: um software gratuito para análise de dados textuais. Temas em Psicologia. v. 21, n. 2, p. 513-518, 2013. Disponível em: http://pepsic.bvsalud.org/pdf/tp/v21n2/v21n2a16.pdf. Acesso em: 04 set. 2020. DOI: http://dx.doi.org/10.9788/TP2013.2-16

DAY, Christopher; SACHS, Judyth. Professionalism, performativity and empowerment: discourses in the politics, polices and purposes as CPD. In: DAY, Christopher; SACHS, Judyth. International handbook on the CPD of teachers. UK: Open University Press, 2004, p. 3-32.

FERREIRA, Janaína da Silva; SANTOS, José Henrique; COSTA, Bruno Oliveira. Perfil de formação continuada de professores de Educação Física: modelos, modalidades e contributos para a prática pedagógica. Revista Brasileira de Ciências do Esporte, v. 37, n. 3, p. 289-298, jul. 2015. Disponível em: https://www.sciencedirect.com/science/article/pii/ S0101328915000566?via\%3Dihub. Acesso em: 15 set. 2020. DOI: https://doi.org/10.1016/j. rbce.2014.01.002

FIORENTINI, Dário; CRECCI, Vanessa. Desenvolvimento profissional docente: um termo guarda-chuva ou um novo sentido à formação?! Formação Docente, v. 5, n. 8, p. 11-23, jun. 2013. Disponível em: https://revformacaodocente.com.br/index.php/rbpfp/article/view/74. Acesso em: 15 set. 2020.

FLETCHER, Tim. Experiences and identities: Pre-service elementary classroom teachers being and becoming teachers of physical education. European Physical Education Review, v. 18, n. 3, p. 380-395, oct. 2012. Disponível em: https://journals.sagepub. com/doi/10.1177/1356336X12450798. Acesso em: 15 set. 2020. DOI: https://doi. org/10.1177/1356336X12450798

GARIGLIO, José Ângelo. O papel da formação inicial no processo de constituição de identidade profissional de professores de Educação Física. Revista Brasileira de Ciências do Esporte, v. 32, n. 2-4, p. 11-28, dez. 2010. Disponível em: https://www.scielo.br/scielo. php? script=sci_arttext\&pid=S0101-32892010000200002\&lng=pt\&nrm=iso\&tlng=pt. Acesso em: 15 set. 2020. DOI: https://doi.org/10.1590/S0101-32892010000200002 
GONÇALVES, Victor Lana; SILVA, Dirceu Santos; MARINS, João Carlos Bouzas. A avaliação do programa segundo tempo universitário na Universidade Federal de Viçosa.

Revista Brasileira de Ciência e Movimento, v. 27, n. 1, p. 150-163, 2019. Disponível em: https://portalrevistas.ucb.br/index.php/RBCM/article/view/9689\#: :text=Concluiu\%2Dse\%20 que\%200\%20PSTU,0\%20mesmo\%20objetivo\%20na\%20UFV. Acesso em: 20 set. 2020. DOI: http://dx.doi.org/10.31501/rbcm.v27i1.9689

HARGREAVES, Andy; O'CONNOR, Michael. Cultures of professional collaboration: their origins and opponents. Journal of Professional Capital and Community, v. 2, n. 2, p. 74-85, April, 2017. Disponível em: https://portalrevistas.ucb.br/index.php/RBCM/article/ view/9689. Acesso em: 15 set. 2020. DOI: https://doi.org/10.1108/JPCC-02-2017-0004

HIGGINS, Steve et al. Developing Great Teaching: Lessons from the international reviews into effective professional development. Project Report. Teacher Development Trust, London, 2015. Disponível em: http://tdtrust.org/about/dgt. Acesso em: 15 set. 2020.

JONES, Robyn Lloyd; ARMOUR, Kathleen; POTRAC, Paul. Constructing Expert Knowledge: A case study of a top-level professional soccer coach. Sport, Education and Society, v.8, n.2, p. 213-229, dec. 2003. Disponível em: https://www.tandfonline. com/doi/abs/10.1080/13573320309254. Acesso em: 14 set. 2020. DOI: http://dx.doi. org/10.1080/13573320309254

MACHADO, Thiago da Silva et al. The practices of pedagogical divestiture in the school Physical Education. Movimento, v. 16, n. 2, p. 129-147, abril/jun., 2010. Disponível em: https://seer.ufrgs.br/Movimento/article/viewFile/10495/27318. Acesso em 15 set. 2020.

MARCON, Daniel; GRAÇA, Amândio Braga dos Santos; NASCIMENTO, Juarez Vieira. Práticas pedagógicas como cenário para a construção do conhecimento pedagógico do conteúdo dos futuros professores de educação física. Journal of Physical Education, v. 23, n. 2, p. 295-306, abril, 2012. Disponível em: http://periodicos.uem.br/ojs/index.php/ RevEducFis/article/view/12462. Acesso em: 15 set. 2020. DOI: https://doi.org/10.4025/ reveducfis.v23i2.12462

MARCON, Daniel; NASCIMENTO, Juarez Vieira; GRAÇA, Amândio Braga dos Santos. A construção das competências pedagógicas através da prática como componente curricular na formação inicial em educação física. Revista Brasileira de Educação Física e Esporte, v. 21, n. 1, p. 11-25, jan./mar. 2007. Disponível em: https://www.revistas.usp. br/rbefe/article/view/16640. Acesso em: 15 set. 2020. DOI: https://doi.org/10.1590/S1807$\underline{55092007000100002}$

MAY, Tim. Pesquisa social: questões, métodos e processos. Porto Alegre: Artmed, 2004.

NÍ CHRÓINÍN, Déirdre Ní; O’SULLIVAN, Mary. From initial teacher education through induction and beyond: a longitudinal study of primary teacher beliefs. Irish Educational Studies, v. 33, n. 4, p. 451-466, feb. 2014. Disponível em: https://www.tandfonline.com/doi/ abs/10.1080/03323315.2014.984387. Acesso em: 15 set. 2020. DOI: $\underline{\text { https://doi.org/10.1080/ }}$ $\underline{03323315.2014 .984387}$

NUNES, Claudio Pinto; OLIVEIRA, Dalila Andrade. Trabalho, carreira, desenvolvimento docente e mudança na prática educativa. Educação e Pesquisa, São Paulo, v. 43, n. 1, p. 65-80, jan./mar. 2017. Disponível em: https://www.scielo.br/scielo.php?script=sci arttext\&pid=S1517-97022017000100066\&lng=pt\&tlng=pt. Acesso em: 08 jul. 2020. DOI: https://doi.org/10.1590/s1517-9702201604145487

OLIVEIRA, Amauri Aparecido Bássoli et al. Formação continuada em projetos e programas sociais esportivos: um estudo de caso. Movimento, v. 22, n. 3, p. 901-916, jul./set. 2016. 
Disponível em: https://seer.ufrgs.br/index.php/Movimento/article/view/57304. Acesso em: 13 set. 2020. DOI: https://doi.org/10.22456/1982-8918.57304

OLIVEIRA, Amauri Aparecido Bássoli; PERIM, Gianna Lepre. (Org.). Fundamentos pedagógicos para o Programa Segundo Tempo: da reflexão à prática. Maringá: Eduem, 2009. p. 208-237.

PIRES, Veruska et al. Identidade docente e educação física: Um estudo de revisão sistemática. Revista Portuguesa de Educação, v. 30, n. 1, p. 35-60, jun. 2017. Disponível em: https://revistas.rcaap.pt/rpe/article/view/7415. Acesso em: 12 set. 2020. DOI: https://doi. org/10.21814/rpe.7415

PIZANI, Juliana et al. Monitoring and pedagogical support of "segundo tempo" programo $f$ ministry of sports. Journal of Physical Education, v. 31, n. 1, p. 1-12, april 2020. Disponível em: http://www.periodicos.uem.br/ojs/index.php/RevEducFis/article/view/42601. Acesso em: 11 set. 2020. DOI: https://doi.org/10.4025/jphyseduc.v31i1.3105

RATINAUD, Pierre. (2009). IRAMUTEQ: Interface de R pour les Analyses Multidimensionnelles de Textes et de Questionnaires [Computer software], 2009. Disponível em: http://www.iramuteq.org. Acesso em: 10 ago. 2020.

RIBEIRO, Sheylazarth Presciliana; ISAYAMA, Helder Ferreira Isayama. F. O Lazer na Política Pública de Esporte: Uma análise da Formação no Programa Segundo Tempo. Revista Brasileira de Ciência e Movimento, v. 23, n.1 p. 103-116, 2015. Disponível em: https://portalrevistas.ucb.br/index.php/RBCM/article/view/5069. Acesso em: 10 set. 2020. DOI: http://dx.doi.org/10.18511/0103-1716/rbcm.v23n1p103-116

SILVA, Dirceu Santos; BORGES, Carlos Nazareno Ferreira.; ROELDES, André de Deus. Políticas públicas de esporte e lazer: o processo de formação do Programa Esporte e Lazer na Cidade de Vitória - ES. Revista Brasileira de Ciências do Esporte, v. 36, n. 3, p. 640-647, jul./set. 2014. Disponível em: https://www.sciencedirect.com/science/ article/pii/S010132891470006X?via\%3Dihub. Acesso em 8 set. 2020. DOI: http://dx.doi. org/10.1590/2179-325520143630007

SILVA, Mauro Sérgio da Silva; BRACHT, Valter Bracht. Intervenção profissional durante a formação inicial: contradições e possibilidades das experiencias docentes precoces em educação física. Motrivivência, v. 1, n. 25, p. 57-78, dez. 2005. Disponível em: https:// periodicos.ufsc.br/index.php/motrivivencia/article/view/4695. Acesso em: 8 set. 2020. DOI: https://doi.org/10.5007/\%25x

SOUZA, Vânia de Fátima Matias et al. Formação Continuada na Implementação do Esporte Educacional na Educação Física Escolar. Pensar a Prática, v. 21, n. 4, p. 845-853, out./dez. 2018. Disponível em: https://www.revistas.ufg.br/fef/article/view/50877. Acesso em: 7 set. 2020. DOI: https://doi.org/10.5216/rpp.v21i4.50877

UNGHERI, Bruno Ungheri; ISAYAMA, Hélder Ferreira Isayama. Os Saberes e a Formação Profissional em Lazer: Uma Análise no Campo das Políticas Públicas. Revista Brasileira de Estudos Pedagógicos, v. 98, n. 249. p. 389-409, maio/ago. 2017. Disponível em: http:// rbep.inep.gov.br/ojs3/index.php/rbep/article/view/3376. Acesso em: 7 set. 2020. DOI: https:// doi.org/10.24109/2176-6681.rbep.98i249.2842

UFMS. Planejamento Pedagógico do Convênio (PPC) do Programa Segundo Tempo Universitário. Campo Grande, MS: Sala do PST Universitário da UFMS, 2018. 
Abstract: This study looked into Continuing Professional Development (CPD) of monitors and the professor who participated in the Segundo Tempo University Program (STUP) at the Federal University of Mato Grosso do Sul (UFMS). It is a descriptive study with a qualitative approach. Iramuteq software was used for data analysis of semi-structured interviews. The results indicated that, while initial CPD activities described in the guidelines of the Program did not occur, weekly activities were essential to CPD. They enabled reflection on the program's methodology according to undergraduate subjects, self-evaluation of teaching and learning, and building practitioners' identity. The program significantly contributed to collective CPD at UFMS aligned with future teaching practice.

Keywords: Public Policy. Social Programs. Professional Training. Sports

Resumen: El objetivo fue analizar el desarrollo profesional docente (DPD) de los monitores deportivos y del profesor que actuaron en el Programa Segundo Tiempo (PST) Universitario implementado en la Universidad Federal de Mato Grosso do Sul (UFMS). Fue una investigación descriptiva, con abordaje cualitativo. Se utilizó el software Iramuteq para el análisis de de los datos de las entrevistas semiestructuradas. Los resultados indicaron que, pese a que las actividades iniciales del PST Universitario no fueron ofrecidas a los monitores y al profesor del núcleo, las actividades semanales fueron fundamentales para el DPD. El trabajo realizado en el programa permitió una reflexión sobre las metodologías indicadas por el programa en consonancia con las asignaturas del programa de grado, la autoevaluación del proceso de enseñanza y aprendizaje y la construcción de la identidad del ser profesor. Como conclusión, el PST Universitario en la UFMS posibilitó el DPD continuo y contextualizado con la futura práctica docente.

Palabras clave: Política Pública. Programas Sociales. Capacitación Profesional. Deportes. 


\section{LICENÇA DE USO}

Este é um artigo publicado em acesso aberto (Open Access) sob a licença Creative Commons Atribuição 4.0 Internacional (CC BY 4.0), que permite uso, distribuição e reprodução em qualquer meio, desde que o trabalho original seja corretamente citado. Mais informações em: http://creativecommons.org/licenses/by/4.0

\section{CONFLITO DE INTERESSES}

Os autores declararam que não existe nenhum conflito de interesses neste trabalho.

\section{CONTRIBUIÇÕES AUTORAIS}

Dirceu Santos Silva: Pesquisador responsável pela pesquisa, participou de todas as fases da pesquisa, concepção, delineamento, análise, interpretação dos dados e revisão final.

Paulo Vinicius Baroni Silveira Donadon: Pesquisador responsável pela coleta de dados, transcrição das entrevistas, processamento dos dados, categoria e interpretação dos dados.

Marina Brasiliano Salerno: Pesquisadora responsável pelo processamento de dados, aplicação dos questionários no programa de análise dos dados, delineamento da metodologia, escolha das categorias e revisão do artigo.

Breno Brey D'auria: Pesquisador responsável pela análise e intepretação dos dados, transcrições das entrevistas, redação do manuscrito e revisão final

Luiza Lana Gonçalves: Pesquisadora responsável pela redação do artigo, crítica intelectual importante ao seu conteúdo, discussão sobre o referencial teórico internacional e aprovação final da versão submetida para revista.

\section{FINANCIAMENTO}

O presente trabalho foi realizado com apoio da Coordenação de Aperfeiçoamento de Pessoal de Nível Superior - Brasil (CAPES) - Código de Financiamento 001.

\section{ÉTICA DE PESQUISA}

O projeto de pesquisa intitulado Políticas Públicas do Ministério do Esporte e os convênios com as instituições públicas de Campo Grande-MS foi encaminhado e aprovado pelo Comitê de Ética de Pesquisa (CEP) da Universidade Federal de Mato Grosso do Sul, CAEE: 25178919.8.0000.0021, Número do Parecer: 3.831.263.

\section{COMO REFERENCIAR}

SILVA, Dirceu Santos; DONADON, Paulo Vinicius Baroni Silveira; SALERNO, Marina Brasiliano; D’AURIA, Breno Brey; GONÇALVES, Luiza Lana.

Desenvolvimento profissional docente no programa Segundo Tempo universitário na Universidade Federal de Mato Grosso do Sul. Movimento (Porto Alegre), v.27, p.e27032, jan./dez. 2021. Disponível em: https://seer.ufrgs.br/Movimento/ article/view/111746. Acesso em: [dia] [mês abreviado]. [ano]. DOI: https://doi. org/10.22456/1982-8918.111746 


\section{RESPONSABILIDADE EDITORIAL}

Alex Branco Fraga*, Elisandro Schultz Wittizorecki*, Ivone Job*, Lisandra Silva*, Mauro Myskiw*, Raquel da Silveira*

*Universidade Federal do Rio Grande do Sul, Escola de Educação Física, Fisioterapia

e Dança, Porto Alegre, RS, Brasil. 